\title{
CORRELATION BETWEEN OXIDATIVE STRESS GENERATION, RETICULAR FIBER DENSITY AND TESTICULAR HISTOMORPHOMETRIC PARAMETERS OF STREPTOZOTOCIN-INDUCED DIABETIC WISTAR RAT
}

\author{
GE Anyanwu ${ }^{1}$ and CA Agbor ${ }^{*}$ \\ ${ }^{1}$ Department of Anatomy, Faculty of Basic Medical Sciences, University of Nigeria, Enugu, Nigeria \\ ${ }^{2}$ Department of Anatomy, Faculty of Basic Medical Sciences, University of Calabar, Nigeria
}

\begin{abstract}
The actual underlying mechanism of alterations in testicular histomorphometric parameters resulting from diabetes-induced oxidative stress is still not well understood because of the absence of supporting evidence from scientific experiments. This study was conducted to investigate the correlation between serum oxidative stress markers with testicular histomorphometric parameters and reticular fiber density of Streptozotocin-induced diabetic Wistar rat. The experiment included twenty eight adult male rats sorted into four groups, Group A (Control), other animals were sorted into treatment groups based on their blood glucose levels after inducing diabetes with $65 \mathrm{mg} / \mathrm{kg} / \mathrm{bw}$ of streptozotocin, Groups B (100 $200 \mathrm{mmol} / \mathrm{l})$, Group C (210 - $250 \mathrm{mmol} / \mathrm{l})$, Group D (260 - $300 \mathrm{mmol} / \mathrm{l})$. At termination, Serum superoxide dimutase (SOD), catalase and melondialdehyde where evaluated using reagent based antioxidant enzyme assay while reticulum stain kits was used to demonstrate for reticular fiber density. Histomorphometric measurements were carried out using ocular micrometer after calibration on a light microscope. Statistical analysis was done using analysis of variance with $p<0.05$ considered significant. Results reveal that the higher the blood glucose levels in diabetic animals, the higher the serum concentration of oxidative stress markers. Density of reticular fiber increased with increase in blood glucose levels, while tubular diameter and epithelial height decreased with increase in increase in hyperglycaemic levels. In conclusion, there was a progressive increase in reticular fiber density and decrease in tubular diameter and epithelial height as a consequence of increase oxidative stress generation in diabetic model.
\end{abstract}

Key words: Diabetes, Histomorphometric parameters, Oxidative stress, Reticular fiber, Testes

\section{Introduction}

Diabetes is thought to affect male reproductive function at multiple levels due to its effect on the endocrine control of spermatogenesis as well as penile erection, sperm quality and cytoachitectural alteration (Aitken and Krause 2002). Reactive oxygen species (ROS) which are increased by hyperglycaemia both in type 1 and 2 diabetes caused by oxidative stress (Beckam et al. 2001) that played an important role in the development of complications in diabetes (Baynes et al. 1999). During prolonged hyperglycaemia, high amount of glucose is produced and made available to the cell and as a result, glucose flux is promoted through glycolytic and tricarboxylic acid pathways (Agbaje et al. 2009), and may lead to overrun in electron transport chain of the mitochondrial thus generating higher amount of ROS and oxidative stress ensues (Brand 2010).

Report shows that the ROS generation at every level of non-enzymatic glycation reaction of proteins produces several intermediate products before ending in advanced glycosylation end product (AGEs). It has

*Author for correspondence: agbor_cyril@yahoo.com 
also been shown that sorbitol and hexosamine pathways can make use of diverted glucose and this process can result in further ROS generation from the metabolism of diverted glucose (Johansen et al. 2005). A correlation between ROS generation with testicular histomorphometric parameters and reticular fiber expression could be found useful in assessing microstructural and histopathological alterations in testes of diabetics. Increase in reticular fiber density around the seminiferous tubules may threaten spermatogenesis and thus leading to infertility (Bhatia et al. 2010). An acceptable scientific experimentation is therefore needed establish the link between altered reticular fiber expression and sustained hyperglycemia in etiology of reproductive dysfunction in diabetic male animal model.

\section{Materials and Methods}

\section{Experimental animals}

Twenty eight adult male Wistar rats were divided into four groups designated A, B, C, D with seven rats in each group. The rats were kept in clean cages and allowed to acclimatize for two weeks in animal house, Department of Anatomy, Faculty of Basic Medical Sciences, University of Nigeria, Enugu, Nigeria.

\section{Induction of hyperglycaemia}

After fasting for twelve hours, hyperglycaemia was induced by administering streptozotocin (STZ) intraperitoneally. STZ was reconstituted in $0.5 \mathrm{M}$ sodium citrate and administered at a dose of $65 \mathrm{mg} / \mathrm{kg} / \mathrm{bw}$.

\section{Confirmation of diabetes and sorting into treatment groups}

Diabetes was confirmed three days after administration of STZ using Accu-Check glucometer (Roche diagnostic, Germany). Animals were sorted into treatment groups based on their blood glucose levels, Groups B (100 - $200 \mathrm{mmol} / \mathrm{l})$, Group C (210 - $250 \mathrm{mmol} / \mathrm{l})$, Group D (260 - $300 \mathrm{mmol} / \mathrm{l})$.

\section{Termination of experiment and collection of samples for analysis}

At termination, the animals were sacrificed with the testes removed and blotted with filter paper. Both right and left testes were weighed together and then suspended in Bouins fluid for fixation, preparatory to histological processing.

\section{Evaluation of oxidative stress markers}

Blood was obtained by cardiac puncture and samples were transported to the laboratory for biochemical study. Oxidative stress marker kits (Sigma-Aldrich Products, Germany) were used to demonstrate for melondialdehyde (MDA), catalase and soperoxide dimutase (SOD).

\section{Reticular fiber examination}

Reticulum stain kits (Roche Diagnostic, German) - Modified Gomori's was used in this research as a staining protocol for reticular fiber and basement membrane examination.

\section{Histomorphometric measurement}

Histomorphometric measurements were carried out using ocular micrometre after calibration on a light microscope. The stage micrometer was $1 \mathrm{~mm}$ long with 100 divisions so each division of the stage micrometer was one one-hundredth of an $\mathrm{mm}(0.01 \mathrm{~mm}$ or $10 \mu \mathrm{m})$. The eyepiece micrometer was divided into 100 units. 30 divisions of the reticle (eyepiece micrometer) corresponded to $200 \mu \mathrm{m}$. Measurements of seminiferous diameter and germinal epithelial heights were taken and recorded. 


\section{Statistical analysis}

Statistical significance of the differences between the groups was determined using one way analysis of variance (ANOVA) with SPSS statistical analysis program version 20.0. $p<0.05$ value was considered as statistically significant levels.

\section{Results}

As shown in Table 1, diabetic animals in Group B with blood glucose concentration of $134.20 \pm 0.71 \mathrm{mmol} / \mathrm{l}$ recorded values of oxidative stress markers that were not statistically significant $(p<0.05)$ when compared to normal control (Group A). However, serum concentration of SOD, catalase and melondialdehyde in Group C and $D$ with mean blood glucose levels of $206.34 \pm 0.76 \mathrm{mmol} / /$ and $274.11 \pm 0.15 \mathrm{mmol} / /$ respectively were significantly $(p<0.05)$ higher when compared to normal control.

Table 1. Serum glucose levels and oxidative stress markers concentration in different experimental groups

\begin{tabular}{|c|c|c|c|c|c|}
\hline \multirow{2}{*}{\multicolumn{2}{|c|}{ Parameters }} & & \multicolumn{3}{|c|}{ Diabetic groups } \\
\hline & & A & B & C & D \\
\hline \multicolumn{2}{|c|}{ Blood glucose $(\mathrm{mmol} / \mathrm{l})$} & $85.98 \pm 0.34$ & $134.20 \pm 0.71^{*}$ & $206.34 \pm 0.76^{\star}$ & $274.11 \pm 0.15^{*}$ \\
\hline \multirow{3}{*}{$\begin{array}{l}\text { Oxidative } \\
\text { Stress } \\
\text { Markers }\end{array}$} & $\mathrm{SOD}(\mathrm{U} / \mathrm{mg} / \mathrm{ml})$ & $3.40 \pm 0.32$ & $4.10 \pm 0.41$ & $5.54 \pm 0.11^{*}$ & $9.51 \pm 0.53^{\star @}$ \\
\hline & Catalase (Katf) & $1.01 \pm 0.73$ & $1.03 \pm 0.71$ & $1.50 \pm 0.65^{\star}$ & $2.29 \pm 0.71 * @$ \\
\hline & $\mathrm{MDH}(\mu \mathrm{mol} / \mathrm{l})$ & $0.73 \pm 0.89$ & $1.95 \pm 0.05$ & $2.13 \pm 0.45^{\star}$ & $2.80 \pm 0.41 * @$ \\
\hline
\end{tabular}

Values are expressed in Mean \pm Standard error. $N=7 .{ }^{*}=$ Values are remarkably higher when compared to Control at $p<0.05$. @ = Values are significantly lower when compared to Group B at $p<0.05$.

\section{Reticular fiber demonstration}

Methenamine silver (Gomori PAM) staining protocol for reticular fiber and basement membrane examination on testicular tissue was negative in group $\mathrm{A}$ (Control) as there was no reticular fiber expressed in the basement membrane (Fig. 1). However, observation showed positive result in group B, C and D which revealed the black color reticular fiber seen round the seminiferous tubules (Figs. 2, 3 and 4). Density of reticular fiber increased with increase in blood glucose concentration. Expression of reticular fiber was most prominent in group D (Fig. 4). Reticular fiber and basement membrane examination are given below:

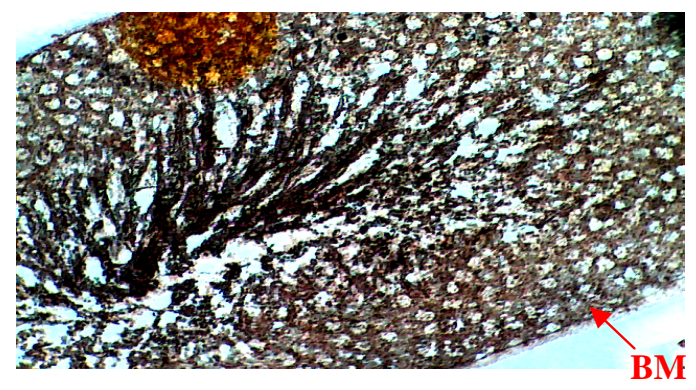

Fig. 1: GROUP A - X400

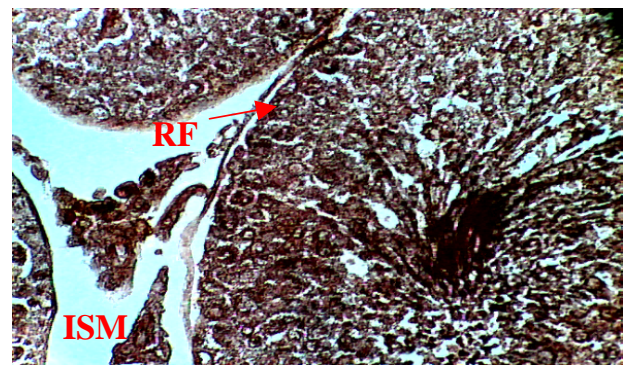

Fig. 2: GROUP B - X400

(BM = basement membrane, ISM = testicular interstitium, RF = recticular fibres). 


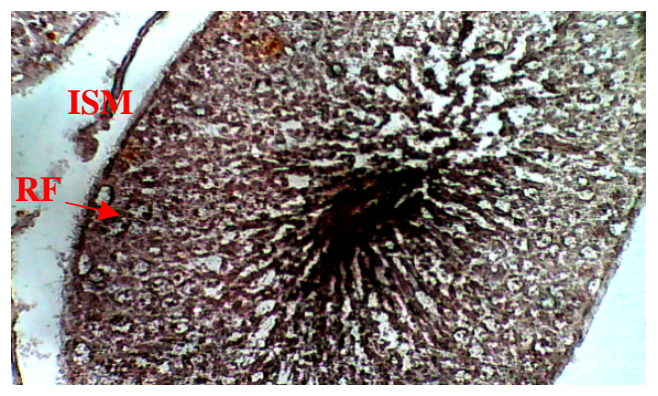

Fig. 3: GROUP C - X400

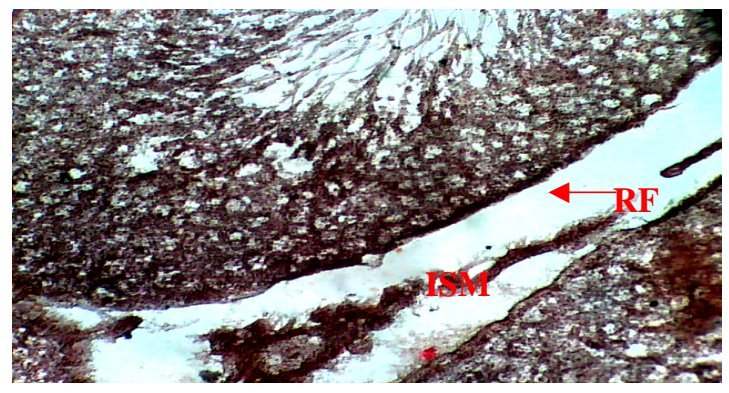

Fig. 4: GROUP D X400

(BM = basement membrane, ISM = testicular interstitium, $\mathrm{RF}=$ recticular fibres).

\section{Histopathological examination}

Group A (Control) revealed testis that had closely packed seminiferous tubules with an intact membrane containing proliferating spermatogonia cells at various stage of maturation. Interstitial cells were prominent in the matrix and the luminal cavity contains flagellae of mature spermatozoa (Fig. 5).

Photomicrograph of testes in Group B showed irregular and shrunken seminiferous tubules. Fewer spermatogenic cell populations on the germinal epithelium and inconsistent cellular associations. The interstitium was irregular and contained Leydig cells (Fig. 6). Section of testes in diabetic groups C and D showed significant alteration in histological structural pattern in the testes. Irregular shaped seminiferous tubules with shrunken lumen where observed. The germinal epithelium had scanty differentiating cells arranged in a coarse pattern and tubular lumen contained very few spermatozoa tails. The intervening interstitium was distorted and cells of leydig were not prominent (Fig. 7 and 8).

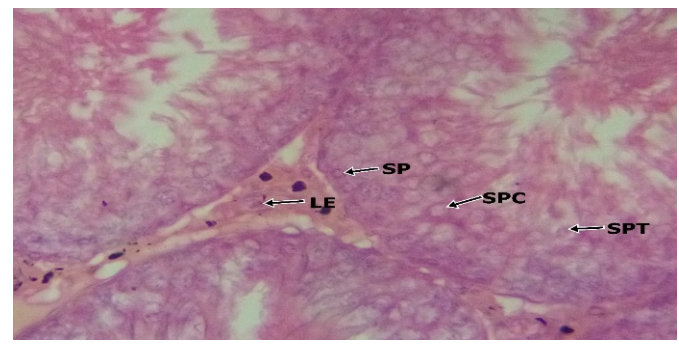

Fig. 5: GROUP A - X400

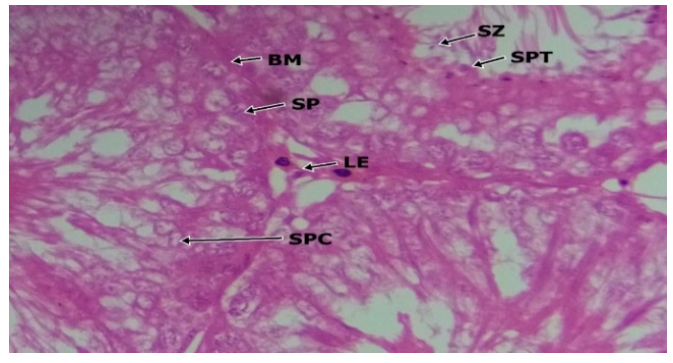

Fig. 6: GROUP B - X400

(BM = basement membrane, $\mathrm{LE}=$ lumen, $\mathrm{LC}=$ leydig cell, $\mathrm{SP}=$ spermatid, $\mathrm{SPC}=$ spermatocytes, $\mathrm{SPT}=$ spermatogonia, $\mathrm{SZ}=$ spermatozoa). 


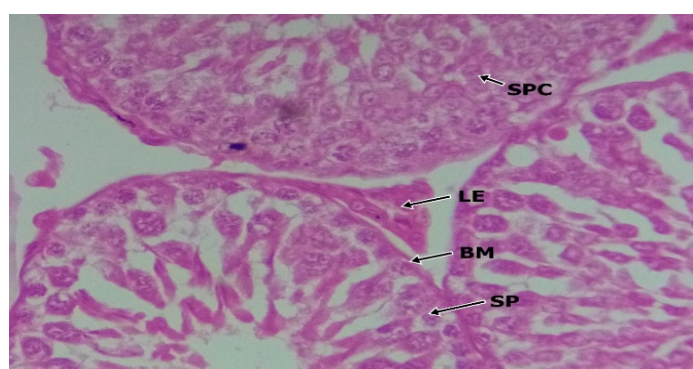

Fig. 7: GROUP C - X400

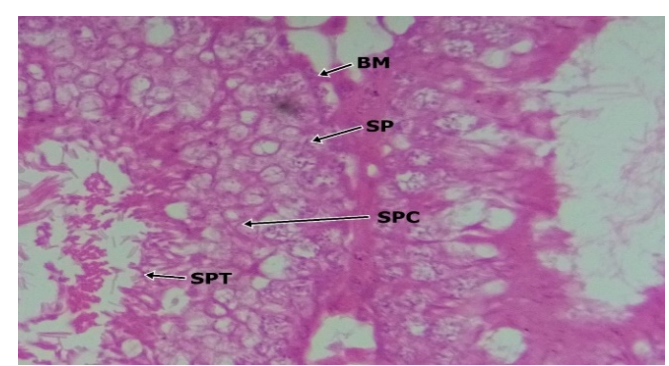

Fig. 8: GROUP D - X400

(BM = basement membrane, $\mathrm{LC}=$ leydig cell, $\mathrm{LE}=$ lumen, $\mathrm{SP}=$ spermatogonia, $\mathrm{SPC}=$ spermatocytes, $\mathrm{SPT}$ $=$ spermatid).

\section{Histo-morphometric parameters}

\section{Tubular diameter}

As shown in Fig. 9, seminiferous tubular diameter was in group B recorded as $249.22 \pm 0.10 \mu \mathrm{m}$ was significantly decreased when compared to $310.81 \pm 0.45 \mu \mathrm{m}$ in Group A (Control). Values in groups $C$ and $D$ were further reduced to $210.00 \pm 0.34 \mu \mathrm{m}$ and $156.43 \pm 0.11 \mu \mathrm{m}$ respectively, both values were significantly $(p<0.05)$ reduced when compared to the Group A (Normal) control and Group B.

\section{Germinal epithelial heights}

Germinal epithelial heights were least in groups $C$ and group $D$, measuring $13.94 \pm 0.55 \mu \mathrm{m}$ and $10.50 \pm 0.72$ $\mu \mathrm{m}$ respectively, and these values were significantly decreased $($ at $p<0.05)$ when compared to epithelial height in control (Group A). However, epithelial height of seminiferous tubules in group B was not significantly lower when compared to group A (Fig. 10).

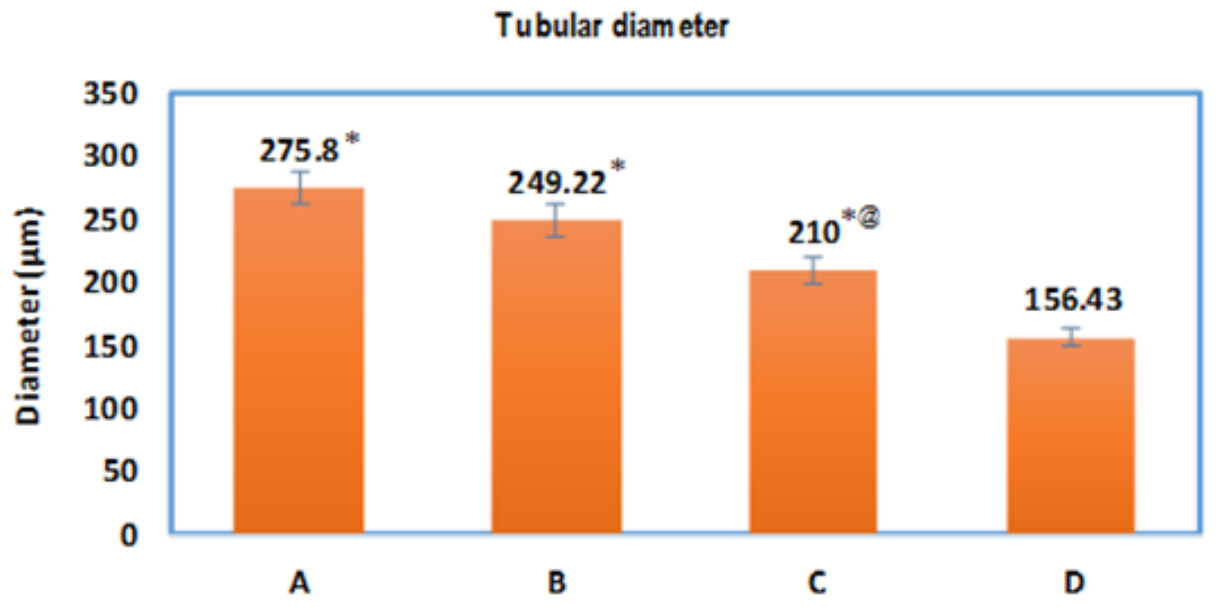

Fig. 9: Comparison of seminiferous tubular diameter in the different experimental groups. 


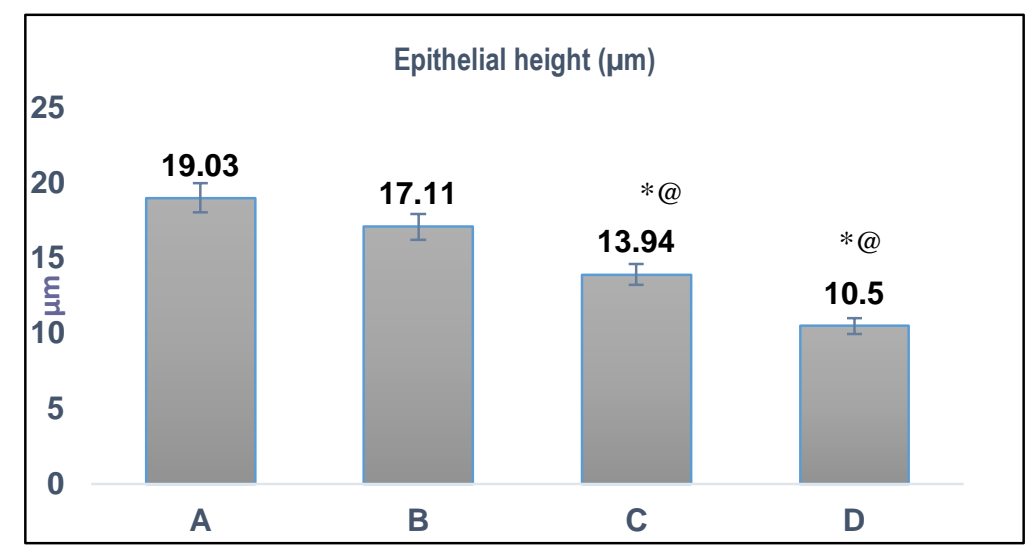

Fig. 10: Comparison of Germinal Epithelial Height in the different experimental groups.

Values are expressed in Mean \pm Standard error. $N=7 .{ }^{*}=$ Values are significantly decreased when compared to Control at $p<0.05$. @ = Values are significantly decreased when compared to Group B at $p<0.05$.

\section{Discussion}

It was observed from this study that oxidative stress markers increased with higher levels of blood glucose in diabetic animals. It has been demonstrated that activities of most ROS producing enzymes like Xanthine oxidase, myeloperoxides, cyclo-oxygenase and NADPH are increased in diabetes. In addition, increase in endothelial Nitric Oxide secretionin diabetics also generates ROS (Dahiru et al. 2016). It is reasonable to suggest that increase in generation of oxidative stress in sustained hyperglycaemia may have resulted in increased reticular fiber density. This may imply that the higher the reticular fibers density, the wider the interstitial matrix and the lower the histomophometric parameters. A possible mechanism could be associated with the effect of hyperglycaemia on somatic cells due to rapid destruction of cell membranes via lipid peroxidation.

Low concentration of ROS generated by leukocytes and immature sperm cells is required for sperm cells to acquire fertilization potentials necessary for the process of capacitation, acrosome reaction and possibly fusion (Saleh et al. 2002), but excessive generation of ROS as in hyperglycaemic condition, without a corresponding balance in antioxidant production capacity may have caused cellular damage observed in this study as shown in increased reticular fiber expression, decrease in seminiferous tubular diameter and germinal epithelial heights. Oxidative stress has been indirectly connected to the clinical consequences of basement membrane integrity and sperm DNA damage which may occur through lipid peroxidation (Chabory et al. 2009, Maker et al. 2009, Anyanwu and Agbor 2020). Mitochondrial exposure to ROS provokes apoptotic process through release of apoptosis inducing factor (AIF) which also causes membrane lipids. High level of ROS will also agitate mitochondrial membrane polarization and activates release of the cytochrome-C protein as a trigger of apoptosis (Maker et al. 2009, Anyanwu et al. 2020).

The less prominent and shrunken seminiferous tubules with loose basement membrane, scanty interstitium, non-visible leydig cells, and distorted germinal epithelium observed in photomicrograph of diabetic groups when compared with normal control group were indicators of testicular tissue damage. Report from Mallidis et al. (2011) has confirmed that STZ-induced diabetes is responsible for alteration in histology of testes, 
reduction and possible death of germ cells in experimental animals. Kilian et al. (2007) gave a confirmation that the normal diameter of seminiferous tubule range between $269 \mu \mathrm{m}$ and $289 \mu \mathrm{m}$ in mature Wister rats and attributed differences in strains to the varied concentration of myoid cells and lamina propria. Therefore, the progressive decrease in tubular diameter and epithelial height as a consequence of increase oxidative stress generation in diabetic model may provide further significant histopathological indices necessary for examination of testicular dysfunction.

\section{Conclusion}

It has been shown from this research that oxidative stress generated in diabetic models was capable of causing increase in density of reticular fiber and the increase was directly proportional to blood sugar concentration. Testicular histo-morphometric parameters (seminiferous tubular diameter and germinal epithelial height) and microstructure were also significantly altered following increase in glucose levels in diabetic models.

\section{Conflicts of interest}

All authors in this research declare that there is no conflict of interest regarding publication of this paper.

\section{Authors' contributions}

The authors Agbor CA and Anyanwu GE contributed equally to this work.

\section{References}

Agbaje I, O'neil J and Czerwiec A (2009). Differences in rat model of diabetes mellitus in study of male reproduction. Int. J. Androl., 33: 709-716.

Ahmed RG (2005). The physiological and biochemical effects of diabetes on the balance between oxidative stress and antioxidant defence system. Medical Journal of Islamic World Academic Science, 15: 31-42.

Aitken RJ and Krause C (2001). Oxidative stress, DNA damage and the Y-chromosome. Reproduction 122: 497-506.

Anyanwu GE and Agbor CA (2020). Assessment of testicular histomorphometric parameters and reticular fibres density on testicular tissue of diabetic Wistar rat placed on Auricularia polytricha. Jordan J. Biol. Sciences, 13: 709-714.

Anyanwu GE, Agbor CA and Audu SJ (2020). Auricularia polytricha restores altered reproductive parameters in streptozotocin-induced diabetic Wistar rat. The Journal of Basic and Applied Zoology, 81:1-9. doi: 10.1186/s41936020-00165-z.

Baynes JW and Thorpe SR (1999). Role of oxidative stress in diabetic complication. Int. Journal Diabetes, 48: 1-9.

Beckman JA, Goldfine AB, Gordon MB, Creager MA. (2001). Ascorbate restores endothelium-dependent vasodilation impaired by acute hyperglycemia in humans. Circulation, 103(12): 1618-23, doi: 10.1161/01.cir.103.12.1618.

Bhatia DK, Sharma AK, Pathania PC and Khauduri NC (2010). Antifertility effect of crude extract of Adiantum lunulatum on reproductive organs of male Wister rats. Int. Journal on Biological Forum, 2(2): 88-93.

Brand MD (2010). The sites and topology of mitochondrial superoxide production. Exp. Gerontol., 45(7-8): 466-472.

Chabory E, Damon C, Lenoir A and Henry-Berger J (2009). Epididymis seleno-independent glutathione peroxidase 5 maintain sperm DNA integrity in mice. J Clin Invest, 119: 2074-2085.

Dahiru T, Aliyu A and Shehu AA (2016). Review of population-based studies on diabetes mellitus in Nigeria. SubSaharan African Journal of Medicine, 3: 59-64. 
Johansen JS, Rychly DJ, Harris AK and Ergul A (2005). Oxidative stress and the use of antioxidant in diabetes: linking basic science to chemical practice. Card. Diabetol., 4(1): 5.

Kilian E, Delport R, Bornman MS and Jageer DTC (2007). Exposure to low level concentration dichlorodipenylt deltamethrin, non-phenol and phytoestrogen has negative effect on the reproductive parameters of male Wistar rat. J. Embryol Androl., 39: 128-135.

Maker K, Agarwal A and Sharma R (2009). Oxidative stress and male infertility. Indian Jmed Res., 129: 357-367.

Mallidis C, Agbaje I, McClure N and Kliesh S (2011). The influence of DM on male reproductive function: a poorly investigated aspect of male infertility. Journal of Urology, 50: 33-37.

Saleh RA, Agarwal A, Kandirali E and Sharma RK (2002) Leukocytospermia is associated with increased reactive oxygen specie production by human spermatozoa. J Fert. Sterility, 78: 1215-1224.

(Manuscript received on 14 April 2020; revised on 11 November 2020) 